Case report

\title{
Rural physicians' scope of practice on remote islands: A case report of severe pneumonia that required overnight artificial airway management
}

\author{
Ryuichi Ohta ${ }^{1}$, and Akira Shimabukuro \\ ${ }^{1}$ Unnan City Hospital, Japan \\ ${ }^{2}$ Okinawa Miyako Hospital, Japan
}

\begin{abstract}
Objective: To clarify the scope of practice on rural islands of Okinawa.

Patient: A 59-year-old man presented to our clinic with shortness of breath. He was intubated due to acute respiratory failure caused by severe pneumonia. We could not transfer him owing to bad weather, and had to continue patient care in the clinic for more than 24 hours.

Discussion: In remote regions, rural physicians may require a broad scope of practice from primary to tertiary care, in addition to preventive and end-of-life care.

Conclusion: This case illustrates the current state of emergency care and unique scope of practice on rural islands of Okinawa.
\end{abstract}

Key words: scope of practice, artificial airway management, emergency transportation, remote island clinic, Okinawa

(J Rural Med 2017; 12(1): 53-55)

\section{Introduction}

In Okinawa, the prefectural airborne medical service and Self-Defense Forces provide aeromedical transport for critically ill patients in remote islands. These services are considered invaluable, especially for emergency care on rural islands, which are geographically isolated and inhabitants there are medically vulnerable ${ }^{1}$. A limited set of equipment is available at remote island clinics, and the number of

Received: November 17, 2016

Accepted: December 26, 2016

Correspondence:Ryuichi Ohta, Unnan City Hospital, 96-1 Iida, Daitocho, Unnan city, Shimane 699-1221, Japan

E-mail: ryuichiohta0120@gmail.com

This is an open-access article distributed under the terms of the Creative Commons Attribution Non-Commercial No Derivatives (by-nc-nd) License $<$ https://creativecommons.org/licenses/by-nc-nd/4.0/>. medical personnel is limited. Self-Defense Forces provide aeromedical retrieval service at Minamidaito island; the average flight time is at least three hours to the mainland of Okinawa ${ }^{2}$. Their flight schedules can be significantly delayed by adverse weather conditions, and they may not be able to fly in poor weather, such as typhoons ${ }^{3,4}$. Care of critically ill patients on the island can last for several hours, but the scope of practice for rural physicians on remote islands has not been previously elucidated. In our clinic, we performed manual ventilation for more than 24 hours on a patient with severe community-acquired pneumonia. This case illustrates some of the challenges faced by physicians on the rural islands of Okinawa and describes the specific scope of practice of rural physicians of remote islands.

\section{Patient}

A 59-year-old Japanese man presented to our clinic on Minamidaito island (Figure 1) of Okinawa prefecture, with shortness of breath for two days. His medical history included alcoholic liver cirrhosis and chronic obstructive pulmonary disease. Medications used included furosemide and spironolactone, but he had discontinued the medications for three months. Initial vital signs were as follows: blood pressure of $84 / 40 \mathrm{mmHg}$, heart rate of 132 beats/min, respiratory rate of 45 breaths $/ \mathrm{min}$, oxygen saturation of $79 \%$ in ambient air, body temperature of $37.6^{\circ} \mathrm{C}$ and Glasgow coma scale of E3V5M6 (total 14/15). Physical examination revealed conjunctival jaundice and inspiratory crackles on both lungs. Laboratory findings were as follows: sodium $136 \mathrm{mEq} / \mathrm{L}$, potassium $3.2 \mathrm{mEq} / \mathrm{L}$, chloride $98 \mathrm{mEq} / \mathrm{L}$, Blood urea nitrogen (BUN) $9 \mathrm{mg} / \mathrm{dL}$, creatine, $1.3 \mathrm{mg} / \mathrm{dL}$, glucose 43 $\mathrm{mg} / \mathrm{dL}$, hemoglobin $13.3 \mathrm{~g} / \mathrm{dL}$, venous $\mathrm{pH} 7.257, \mathrm{HCO}_{3} 11.0$ $\mathrm{mEq} / \mathrm{L}$, and anion gap $30 \mathrm{mEq} / \mathrm{L}$. With a diagnosis of septic shock from bacterial pneumonia, we performed intubation 


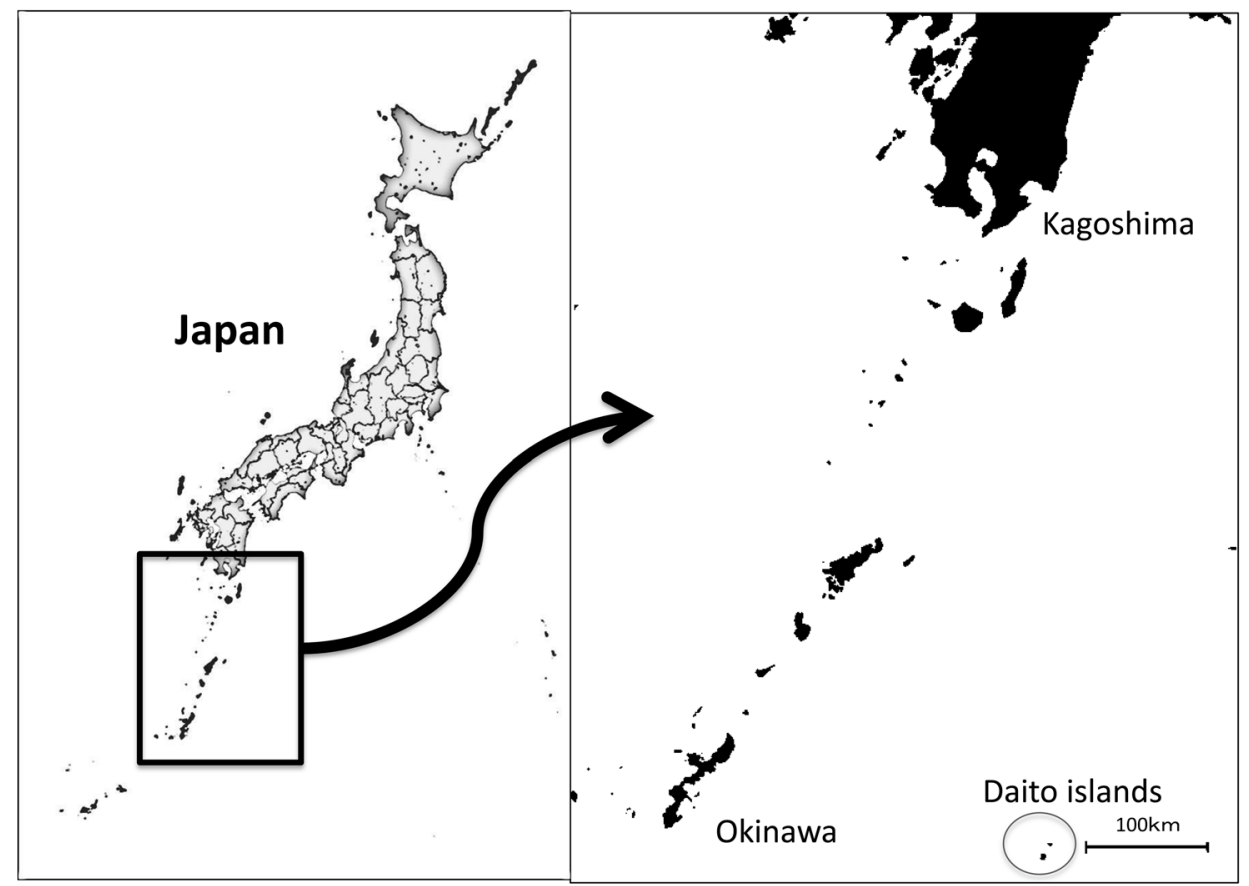

Figure 1 Location of Daito islands. Daito islands consist of Minamidaito island, located to the south, and Kitadaito island, to the north.

for respiratory failure. We started fluid resuscitation and inotrope administration. A plain radiograph was not obtained. Continuous infusion of midazolam was initiated.

Two hours after arrival, following stabilization of vital signs, we called for emergency transport services. However, the Self-Defense Forces helicopter was unable to fly due to bad weather. A nurse, a medical trainee, and the first author performed hourly vital sign measurement and manual ventilation. The patient eventually stayed in the clinic on the day of the visit.

Twenty-two hours after initial presentation, all midazolam samples in the clinic were exhausted. A courageous fisherman offered support and brought a refill to our clinic from an affiliated clinic on a nearby island, $8 \mathrm{~km}$ away. Twenty-seven hours after initial presentation, the Self-Defense Forces helicopter finally arrived and safely transported the patient to the main island of Okinawa.

\section{Discussion}

This case illustrates the current state of emergency care and the scope of practice of rural physicians on remote islands of Okinawa. Most of the islands of Okinawa have only one medical institution on each island. Clinics are outpatient-based ${ }^{5}$. On remote islands such as Kitadaito and Minamidaito Islands, which are more than $400 \mathrm{~km}$ away from the main island of Okinawa, aeromedical transportation is provided solely by a Self-Defense Forces helicopter. The minimum time required for transportation is four hours from initial evaluation to completion of aeromedical transport. Transportation can sometimes be delayed by bad weather, and severely ill patients may have to be observed in island clinics. Previous literature has made proposals regarding the types of medical devices and drugs that should be provided at isolated rural clinics ${ }^{6,7)}$, but to our knowledge, no such proposal exists regarding the amount of drugs to be stocked. Although there are likely similar cases on remote islands in other parts of Japan and elsewhere, we could not find any published report describing such cases. In the future, the description of cases like ours can promote emergency preparedness in isolated clinics.

This case shows that physicians on remote islands need high-level skills for care and emergency medicine. There is a need for primary to tertiary level emergency care as well as primary health care, preventive medicine and end-of-life care as the only physician on remote islands of Okinawa (Figure 2). For example, in severe emergency cases, rural physicians need to stabilize the patient's condition by intubation, insertion of a central venous catheter, or use of emergency medicines, as in the case described here. When physicians are presented with trauma cases, they need to perform hemostatic treatments and tube thoracotomy in cases of 


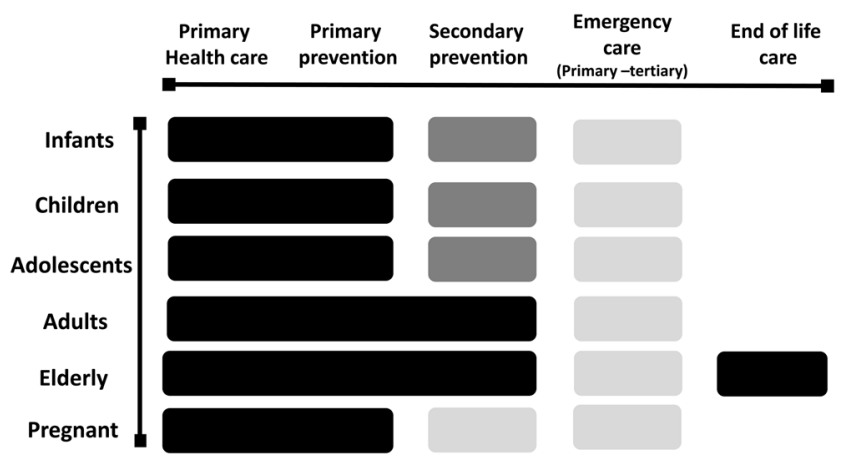

Figure 2 Scope of practice of physicians on rural islands of Okinawa. The vertical line shows categories of age, and the horizontal line shows categories of care. Density of bars indicates the frequency of clinical situations.

traumatic pneumothorax. In addition, in dealing with pediatric and obstetric cases, physicians need to communicate with specialists in hospitals on the mainland of Okinawa, as well as performing procedures usually performed by specialists in hospitals, such as management of neonatal sepsis, usage of uterine contraction inhibitors and assistance with childbirth. In the case described here, an approach to emergency cases by only a physician and a nurse was inevitable and difficult, but it conveys the breadth of scope of practice of rural physicians on remote islands of Okinawa ${ }^{8}$. The wide range of hands-on experiences gained on remote islands may contribute to maintenances and improvement of skills and knowledge'). The scope of practice is also greatly affected by characteristics and contexts of physicians, as well as factors such as being male and experiences in remote areas that can widen the scope of practice ${ }^{10,11}$. In the future, clarifying the scope of practice in clinics in remote areas such as the rural islands of Okinawa will contribute to an enhanced medical care system and improved training for physicians who plan to work in these regions.

\section{Conclusion}

We treated a patient with severe community-acquired pneumonia who required overnight advanced airway management at a clinic located on a remote island of Okinawa,
Japan. Rural physicians need a broad scope of practice on rural islands of Okinawa.

Conflict of Interest: The authors state that they have no Conflict of Interest.

\section{Acknowledgments}

We would like to thank the patient and patient's family who approved this paper.

\section{References}

1. Yi JW, Lee KE, Kim YH, et al. Helicopter patient transportation service on the Ulleung Island, South Korea. Air Med J 2014; 33: 314-319. [Medline] [CrossRef]

2. Ochi M. The situation of emergency transport in Minamidaito Island. Okinawa Medical Journal 1990; 27: 270-272.

3. Kinjo T, Tokuda Y. Epidemiologic analysis for emergency transportation of patients from a remote island clinic to mainland hospitals in Okinawa. Jpn Prim Care 2007; 30: 40-44.

4. Nakashima Y. The current situation and the problem of transport by helicopter in island area (Hagi City Mishima) in Yamaguchi Prefecture. Journal of Japanese Society for Aeromedical Services 2010; 11: 23-26 (in Japanese).

5. Motomura K. Reflective practice and situational learning in island clinics. Journal of the Japan Primary Care Association 2012; 35: 165-167 (in Japanese). [CrossRef]

6. Rothkopf L, Wirshup M. A practical guide to emergency preparedness for office-based family physicians. Fam Pract Manag 2013; 20: 13-18. [Medline]

7. Toback SL. Medical emergency preparedness in office practice. Am Fam Physician 2007; 75: 1679-1684. [Medline]

8. Fuziwara S. Emergency medical care in remote islands. From a remote island clinic: Island physicians alone? ER Magazine 2009; 6: 514-518.

9. Peterson LE, Blackburn B, Peabody M, et al. Family physicians scope of practice and American Board of Family Medicine recertification examination performance. J Am Board Fam Med 2015; 28: 265-270. [Medline] [CrossRef]

10. Hutten-Czapski P, Pitblado R, Slade S. Short report: Scope of family practice in rural and urban settings. Can Fam Physician 2004; 50: 1548-1550. [Medline]

11. Wong E, Stewart M. Predicting the scope of practice of family physicians. Can Fam Physician 2010; 56: e219-e225. [Medline] 